Article

\title{
Spectroscopic and Kinetic Characterization of Peroxidase-Like $\pi$-Cation Radical Pinch-Porphyrin-Iron(III) Reaction Intermediate Models of Peroxidase Enzymes
}

\author{
Samuel Hernández Anzaldo ${ }^{1}$, Uriel Arroyo Abad ${ }^{1}$, Armando León García ${ }^{1}$, \\ Daniel Ramírez Rosales ${ }^{2}$, Rafael Zamorano Ulloa ${ }^{2}$ and Yasmi Reyes Ortega ${ }^{1, *}$ \\ 1 Centro de Química Instituto de Ciencias, Benemérita Universidad Autónoma de Puebla. Edificio 103H, \\ Ciudad Universitaria, Col. Jardines de San Manuel, Puebla, Pue. 72570, Mexico; \\ samuel.hernandezan@correo.buap.mx (S.H.A.); uri_creek@hotmail.com (U.A.A.); \\ armando_leon2@yahoo.es (A.L.G.) \\ 2 Instituto Politécnico Nacional, ESFM, Ave. Instituto Politécnico Nacional S/N, Edif. 9 U.P. Zacatenco, \\ Col. San Pedro Zacatenco, México City 07738, Mexico; danielesfm@yahoo.com.mx (D.R.R.); \\ davozam@yahoo.com (R.Z.U.) \\ * Correspondence: yasmi.reyes@correo.buap.mx; Tel.: +52-222-229-5500 (ext. 7292)
}

Academic Editors: Jose M. Palomo and Chris Frost

Received: 29 April 2016; Accepted: 13 June 2016; Published: 27 June 2016

\begin{abstract}
The spectroscopic and kinetic characterization of two intermediates from the $\mathrm{H}_{2} \mathrm{O}_{2}$ oxidation of three dimethyl ester [(proto), (meso), (deuteroporphyrinato) (picdien)]Fe(III) complexes ([FePPPic], [FeMPPic] and [FeDPPic], respectively) pinch-porphyrin peroxidase enzyme models, with $s=5 / 2$ and $3 / 2 \mathrm{Fe}(\mathrm{III})$ quantum mixed spin (qms) ground states is described herein. The kinetic study by UV/Vis at $\lambda_{\max }=465 \mathrm{~nm}$ showed two different types of kinetics during the oxidation process in the guaiacol test for peroxidases (1-3 + guaiacol $+\mathrm{H}_{2} \mathrm{O}_{2} \rightarrow$ oxidation guaiacol products). The first intermediate was observed during the first $24 \mathrm{~s}$ of the reaction. When the reaction conditions were changed to higher concentration of pinch-porphyrins and hydrogen peroxide only one type of kinetics was observed. Next, the reaction was performed only between pinch-porphyrins-Fe(III) and $\mathrm{H}_{2} \mathrm{O}_{2}$, resulting in only two types of kinetics that were developed during the first $0-4 \mathrm{~s}$. After this time a self-oxidation process was observed. Our hypotheses state that the formation of the $\pi$-cation radicals, reaction intermediates of the pinch-porphyrin-Fe(III) family with the ligand picdien [ $N, N^{\prime}$-bis-pyridin-2-ylmethyl-propane-1,3-diamine], occurred with unique kinetics that are different from the overall process and was involved in the oxidation pathway. UV-Vis, ${ }^{1} \mathrm{H}-\mathrm{NMR}$ and ESR spectra confirmed the formation of such intermediates. The results in this paper highlight the link between different spectroscopic techniques that positively depict the kinetic traits of artificial compounds with enzyme-like activity.
\end{abstract}

Keywords: pinch-porphyrins; peroxidases models; $\pi$-cation radical; spectroscopic studies

\section{Introduction}

Enzymes are proteins that act like natural catalysts, producing a huge increase in the reaction rate by lowering the energetic barrier in the transition state of a process [1,2]. Scientists have tried to mimic this power using synthetic products [2,3]. In this context, peroxidases are among several proteins targeted for replacement by coordination compounds, specifically synthetic metalloporphyrins, due to their similarity to the prosthetic groups found in peroxidases. The catalytic process is performed throughout the oxidation of the transition metal, iron in the case of the metalloporphyrins, and with the same macrocyclic organic ligand. Additionally, magnetic phenomena in iron porphyrins 
are responsible for the versatile behavior of their chemistry. The spin state of the iron ion is governed by the ligand's field attachment force and the symmetry of the surrounding ligands [4]. Biologically speaking, the magnetic state of proteins containing the heme group has been recognized as a marker of chemical coordination as well as of subtle biochemical properties [5]. In some biological compounds like ferricytochrome $c^{\prime}$, horseradish peroxidase and the ferric ion in complexes of tetragonal symmetry, the ground state is composed of the linear combination of two spin states, $s=5 / 2, s=3 / 2$, phenomenon known as quantum mixed spin [6,7]. As well, it has been reported to have a five-coordinated Fe(III)-pinchporphyrins to weak-field anions that were characterized as qms systems which show magnetic properties that span a continuum of magnetic states between the pure $s=1 / 2$ and the pure $s=5 / 2$ spin states. Previously, Reed and Guiset [8] proposed a qualitative magnetochemical series based on the iron ligand field deduced from the mixing of $s=3 / 2,5 / 2$ spin states in porphyriniron(III) compounds.

Peroxidases usually form free radicals that immediately become into dimers that act as substrates or cause oxidation to the species in the system. The rapid reaction rate makes difficult to envision intermediate compounds, however, fine-tuned spectroscopies, like ESR, have being applied due to its sensitivity which allow us to describe the nature of the bond in the complex and even to detect the coupling between species. Previously, we reported a detailed spectroscopy and catalytic studies of a series of pinch-porphyrin-Fe(III) systems, namely [Fe(III)(picdien)(protoporphyrinato dimethyl ester $]=[$ FePPPic $],[$ Fe(III)(picdien $)($ mesoporphyrinato dimethyl ester $)]=[$ FeMPPic $]$ and $[\mathrm{Fe}(\mathrm{III})$ (picdien)(deuteroporphyrinato dimethyl ester) $]=[$ FeDPPic $]$, although the best kinetic model of peroxidases is yet to be reported (Figure 1). The pinch-ligand significantly alters the iron environment in these complexes, producing physical characteristics of qms of the Fe(III) which correlate with catalytic activity [3]. Overall, it is clear that the chain size of the pinch-axial ligands on the structure, the qms of $\mathrm{Fe}(\mathrm{III})$, and the ratio of the mixtures of $s=3 / 2,5 / 2$ spin states have a correlation to the catalytic activity as peroxidases. One of the most difficult challenges in the catalytic mechanism of peroxidases has been the demonstration of the existence of its intermediates, compounds I and II. These intermediates have a ferryl $\mathrm{Fe}(\mathrm{IV})=\mathrm{O}$ at high spin and free radical. Besides, the unpaired spins of the ion $\mathrm{Fe}(\mathrm{IV})$ are coupled with the radical, giving a total spin of 3/2, which allowed us to see the intermediate by an ESR signal with $\mathrm{g} \sim 4$. In this paper we report in situ spectroscopic studies using UV-Vis, ${ }^{1} \mathrm{H}-\mathrm{NMR}$ and ESR and the description of the catalytic steps in the formation of compounds I and II.

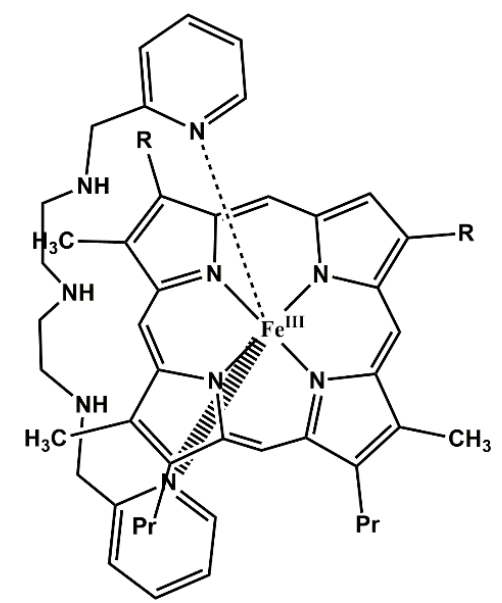

Figure 1. Pinch-porphyrins. When $\mathrm{R}=-\mathrm{CH}=\mathrm{CH}_{2}$ FePPPic; $\mathrm{R}=-\mathrm{CH}_{2}-\mathrm{CH}_{3}$ FeMPPic and $-\mathrm{H}$ FeDPPic. $\operatorname{Pr}=$ methylpropionate.

\section{Results and Discussion}

Almost 40 years ago, Peters and Dundford rose the question about the mechanism of compound I formation [9]. Although it was thought to be a reversible substrate complex, the final conclusion was 
that the formation of the intermediate mostly involves an irreversible, 2-electron equivalent oxidation of the enzyme; nevertheless, some authors would disagree due to the emergence of the location in the oxidizing equivalents which may be different in different enzymes [10]. As well, there is plenty of information that a reversible enzyme-substrate complex (termed compound 0 ) is involved in the pathway towards the complete oxidation of the peroxidases although its structure has remained controversial [11].

The kinetic study by UV-Vis swept at $500 \mathrm{~nm}$ of 1-3 (Figure 2) shows that under these conditions the limiting step in their oxidation is the formation of compound I, since the first signal at $\sim 1 \mathrm{~s}$ is rapidly transformed into the next one belonging to compound II at $\sim 3 \mathrm{~s}$. As we previously discussed, 1, 2 and 3 are oxidized by themselves and as seen in Figure 2, after the formation of compound II the absorption disappears after $4 \mathrm{~s}$. Additionally, a saturation is seen when the ideal concentration is surpassed $\approx 10$ times and the UV-Vis swept is not fast enough to detect the formation of either compound I or II.
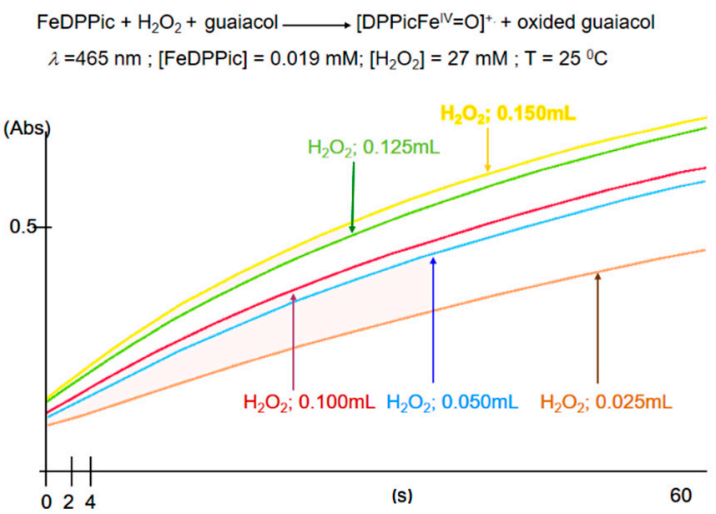

(a)

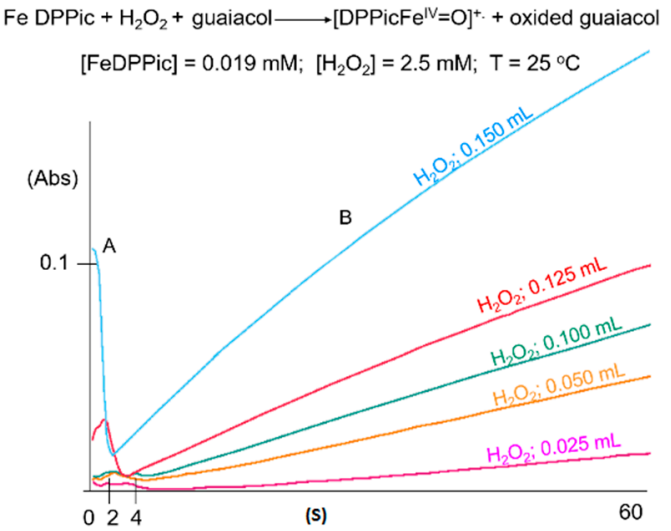

(b)

Figure 2. (a) Single kinetics showing only the guaiacol oxidation products; (b) Two types of kinetics, oxidation of A pinch-porphyrin and $\mathbf{B}$ guaiacol, or three in some cases, were observed when $2.5 \mathrm{mM}$ $\left[\mathrm{H}_{2} \mathrm{O}_{2}\right]$ was added, one magnitude order lower than for activity catalytic studies.

When the guaiacol tests were performed to establish the conditions in which the pinch-iron porphyrin acts at its best as a peroxidase (new-pinchporphyrin complexes with quantum mixed spin ground state $s=5 / 2,3 / 2$ of iron (III) and their catalytic activity as peroxidase [12]), two kinetic curves were observed: $\mathbf{A}$ and $\mathbf{B}$. In these experiments the concentrations of pinch porphyrin-Fe(III) and guaiacol were kept constant and the assays were performed in a 123-156 mM range of aqueous hydrogen peroxide concentrations. The kinetic curve A was seen in the first $4 \mathrm{~s}$ of the reaction and after this time the products of guaiacol oxidation formed curve B (Figure 2a,b). Having established the approximate concentrations of [FePPPic], [FeMPPic] and [FeDPPic] where they show the two kinetic curves, we proceeded to assess the optimum concentrations of peroxide to observe only the kinetics $\mathbf{A}$. The conditions were as follow: $0.0123 \mathrm{mM}$ for [FePPPic], $0.134 \mathrm{mM}$ for [FeMPPic] and $0.25 \mathrm{mM}$ for [FeDPPic] (Figure 3), noticing that they showed very similar kinetic behavior. In the case of [FePPPic] the formation of compounds I and II was so rapid that it was only possible to observe the disappearance step of the pinch porphyrin. Many different conditions were tried to carry out this reaction and was still not possible to see the formation of the intermediates. The reaction mixtures in these assays only contained the pinch porphyrin-Fe(III) compounds and $\mathrm{H}_{2} \mathrm{O}_{2}$, therefore, the formed curves could only correspond to the formation of the compounds I (ferryl $\pi$-cation radical) and compound II (ferryl $\pi$-cation), the intermediates of the catalytic peroxidase enzymes. In each test performed, it was also possible to observe a color change in the solutions from green to red corresponding to the depletion of $\mathbf{A}$ and the formation of $\mathbf{B}$, as shown in the catalytic activity test of horseradish peroxidase. All assays were performed at $\lambda=500 \mathrm{~nm}$ and $298 \mathrm{~K}$. 
Figure 3 shows four reaction kinetic curves of the model compounds. At $0.35 \mathrm{~s}$ the reaction rate is extremely fast and probably correspond to the [P-Fe(III)- $\left.\mathrm{O}_{2} \mathrm{H}_{2}\right]$ complex, followed by a change and a curve with a steeper slope until $0.6 \mathrm{~s}$ time. Later, at $0.5 \mathrm{~s}$ the reaction follows slower kinetics, and finally, the slope is newly more positive informing of an increasing in the reaction rate. In Figure 3 we have suggested what step of the mechanism corresponds to each kinetic curve.

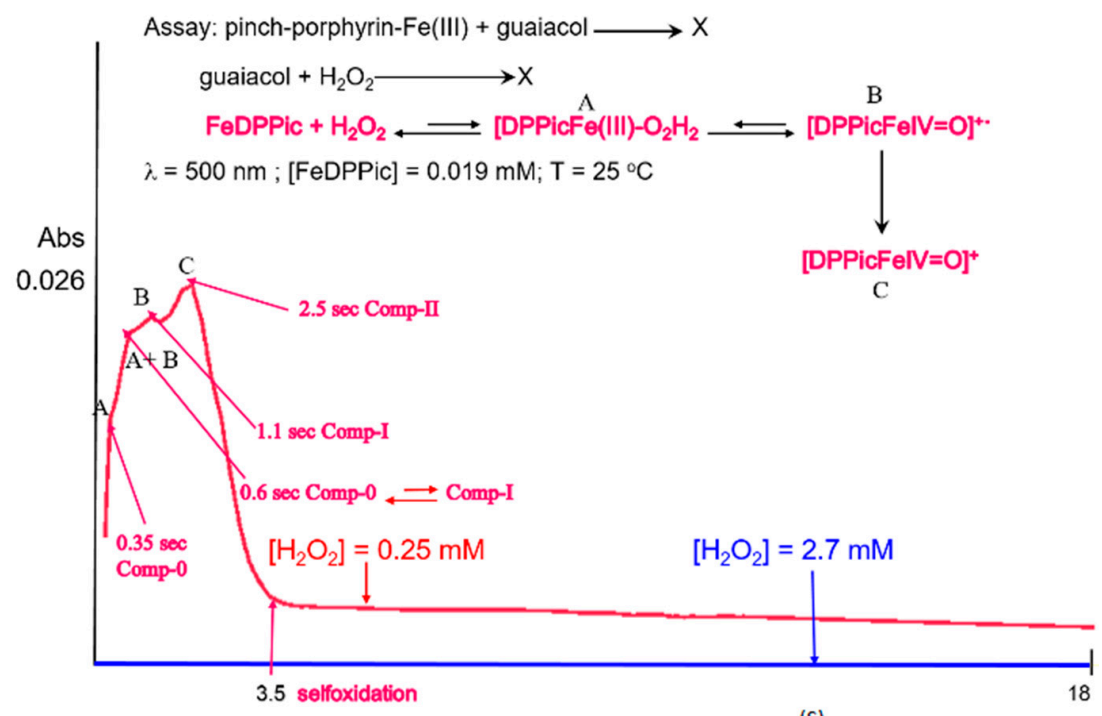

(S)

Figure 3. Kinetic pathway of the reaction $[\mathrm{FeDPPic}]_{(\mathrm{MeOH})}+\mathrm{H}_{2} \mathrm{O}_{2(\mathrm{aq})}$ at the first four seconds of reaction and at $500 \mathrm{~nm}$ (). The blue line () corresponds to the condition with the $\mathrm{H}_{2} \mathrm{O}_{2(\mathrm{aq})}$ concentration one magnitude order higher.

Peroxidase activity in biological systems was first reported in the 19th century [13] and a reaction mechanism was proposed for these enzymes (Scheme 1).

$$
\begin{aligned}
& \mathrm{HRP}+\mathrm{H}_{2} \mathrm{O} \rightleftharpoons \mathrm{HRP}---\mathrm{O}_{2} \mathrm{H}_{2} \\
& \mathrm{HRP}-\mathrm{O}_{2} \mathrm{H}_{2} \longrightarrow \mathrm{HRP}-\mathrm{I}+\mathrm{H}_{2} \mathrm{O} \\
& \mathrm{HRP}-\mathrm{I}+\mathrm{AH}_{2} \longrightarrow \mathrm{HRP}-\mathrm{II}+\cdot \mathrm{AH} \\
& \mathrm{HRP}-\mathrm{II}+\mathrm{AH}_{2} \longrightarrow \mathrm{HRP}+\cdot \mathrm{AH}+\mathrm{H}_{2} \mathrm{O}
\end{aligned}
$$

Scheme 1. The normal peroxidase cycle. HRP Horseradish peroxidase, $\mathrm{HRP}-\mathrm{O}_{2} \mathrm{H}_{2}$ Compound 0, HRP-I compound-I, HRP-II compound-II.

It has been shown that compound 0 is formed quickly but the complicated O-O cleavage is the limiting step of the peroxidase cycle [14]. This is a major contribution for the decrease of the rate in the second kinetic trace. After this second step, compound II is produced quickly as the guaiacol oxidation is carried out. The mechanism matches perfectly with the kinetic steps of the pinch-porphyrin oxidation process as well as for its stages.

\section{1. $U V-V i s$}

The UV-Vis spectra of 1-3 showed notable changes compared with the parent compounds. The Soret band decreased until quenched when the pinch-porphyrins auto-oxidized because there was no guaiacol in the reaction medium. Electronic $d-d$ transitions were shifted from $487.5 \mathrm{~nm}$ for [FePPPic] to $520 \mathrm{~nm}$ and from $605 \mathrm{~nm}$ to $690 \mathrm{~nm}$ for [PPPicFe ${ }^{\mathrm{IV}}=\mathrm{O}^{+\cdot}$ (Figure 4), from $480 \mathrm{~nm}$ for [FeMPPic] to $522 \mathrm{~nm}$ for $\left[\mathrm{MPPicFe}{ }^{\mathrm{IV}}=\mathrm{O}^{+\cdot}\right.$ (Supplementary Materials Figure S1), and for [FeDPPic] $d-d$ band from 
$476 \mathrm{~nm}$ to $520 \mathrm{~nm}$, from $587 \mathrm{~nm}$ to $690 \mathrm{~nm}$ for [DPPicFe ${ }^{\mathrm{IV}}=\mathrm{O}^{+\cdot}$ (Supplementary Materials Figure S2). A change in color from green to red is observed. The UV-Vis studies showed that for this spectroscopy the very rapid pinch-porphyrin oxidation did not provide an opportunity to observe the formation of compound I and later the signal of compound II, due to a higher rate of its transformation; however, kinetic and ESR studies showed signals typical of compound I.

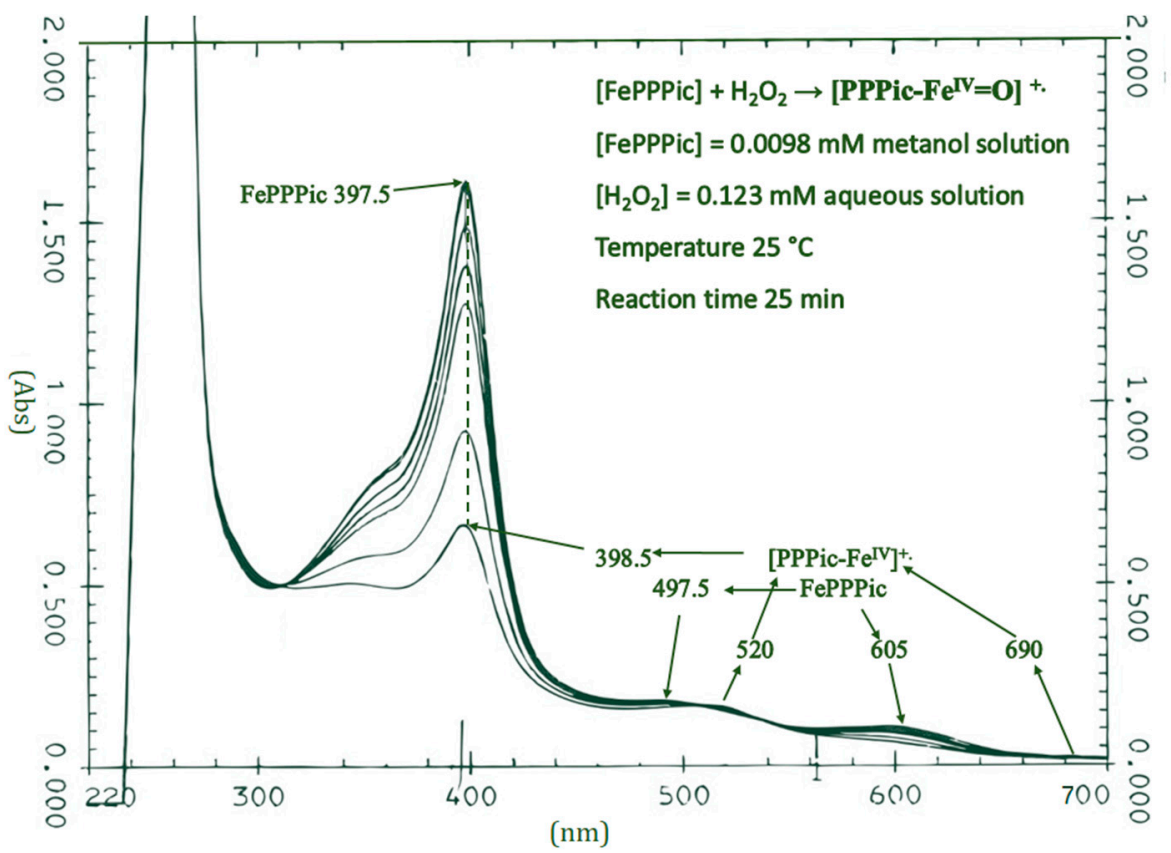

Figure 4. Snapshots of [FePPPic] ${ }^{+}$. formation observed for $25 \mathrm{~min}$. Soret bands decrease indicating that the [FePPPic] is being auto-oxidized because of the absence of guaiacol in the reaction media, similar to HRP-I (compound I of horseradish peroxidase) behavior in an excess of hydrogen peroxide, which reduces compound I. $d-d$ transitions energetically change showing a new spectrum.

UV-Vis spectral data of compound I and compound II for native peroxidase enzymes or their model compounds, have shown considerable differences [15-17].

In Table 1 already reported UV-Vis data are shown for selected native peroxidases and model compounds, and the UV-Vis data for $\left[\mathrm{PP}-\mathrm{Fe}^{\mathrm{IV}}=\mathrm{O}\right]$. It is clear that the $d-d$ transition $\lambda_{\max }$ values are in accordance with other reports [7,17-25]. It was not possible to do the same with the Soret bands because there is a destruction of the pinch-porphyrin rings in the pinch-porphyrin-I and II, which proved that these reaction intermediates are very reactive.

Table 1. Selected $\lambda_{\max }$ from different sources of compound I.

\begin{tabular}{ccc}
\hline Compound Sources & $\lambda_{\max } \mathbf{( n m )}$ & Reference \\
\hline Horseradish Peroxidase-I & 475,530 & {$[7]$} \\
Horseradish Peroxidase-I & 529,555 & {$[18]$} \\
Cytochrome P450-I & 515,572 & {$[19]$} \\
Cytosolic Heme Binding Protein-I & 540,547 & {$[20]$} \\
Heme-thiolate Peroxygenase-I & 538,571 & {$[21]$} \\
Hemoglobin I (from Lucina pectinate)-I & 519,650 & {$[22]$} \\
Chloro(2-oxa-3-oxotetramesitylporphinato)Fe(III) & 556,601 & {$[23]$} \\
Chloro(2-oxa-3-oxotetrakis(2,6-dichlorophenyl)porphinato)Fe(III) & 560,610 & {$[24]$} \\
[meso-Tetrakis(2,4,6-trimethyl-3-sulfonatophenyl)-porphinato]Fe(III) & 526,580 & {$[25]$} \\
[FePPPic]-I & 520,690 & This work \\
[FeMPPic]-I & $522,-$ & This work \\
[FeDPPic]-I & 520,690 & This work \\
\hline
\end{tabular}




\section{2. ${ }^{1} H-N M R$ of Compound I}

Previously we reported the ${ }^{1} \mathrm{H}-\mathrm{NMR}$ analysis assignment for the pinch-porphyrin complexes Figure 4 [3] according to Figure 5.

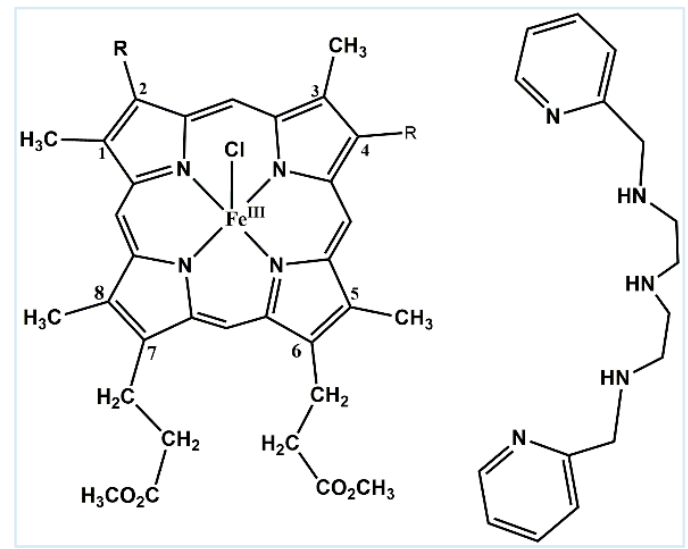

Figure 5. Precursors of the Fe(III)-dimethyl ester porphyrin and 1,9-bis-(2-piridyl)-2,5,8-triazanonane (Picdien). Protoporphyrin $\mathrm{R}=-\mathrm{CH}=\mathrm{CH}_{2}$, Mesoporphyrin $\mathrm{R}=-\mathrm{CH}_{2}-\mathrm{CH}_{3}$, Deuteroporphyrin-H.

Overall, the relaxation times values (T1) for Fe(III)-pinch porphiryns (parent compounds) are visible as downfield-shifted signals, and they are usually assigned according to their intensity (from $x$ to $s y)$. The signals with the highest intensity and the best definition belong mostly to the $\mathrm{CH}_{3}$ groups of the heme, which are more distant of the paramagnetic center with shorter relaxation times. These methyl groups show isotropic shifts at higher frequencies by the strong electronegativity coming from the Fe(III) ion. This electronegativity is so high that it strongly attracts both pi and sigma electrons of the methyl groups, compressing their electron density. The signals of medium intensity are due to the $\mathrm{H} \alpha$ of the vinyl and propionate moieties of the heme and to the $\mathrm{H} \beta$ protons of the proximal picdien (Figure 6) [26-28].

(a)

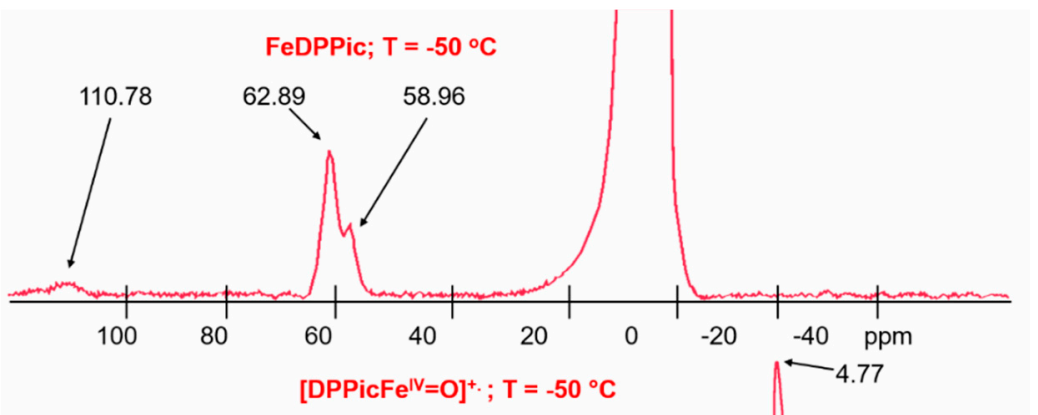

(b)

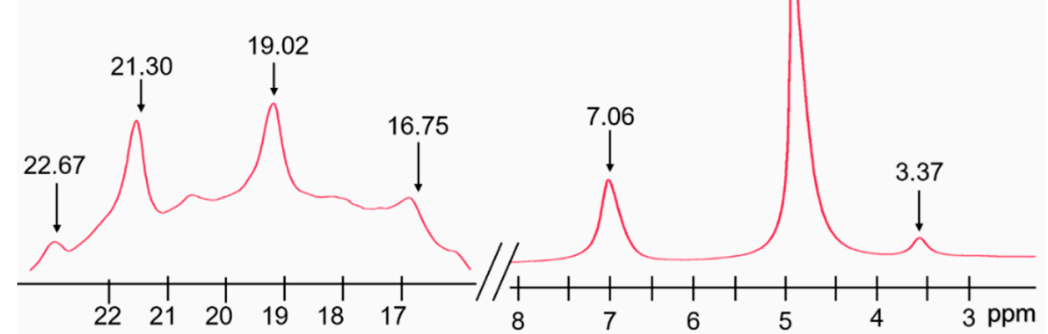

Figure 6. (a) ${ }^{1} \mathrm{H}-\mathrm{NMR}$ of [FeDPPic] with chemical shifts of meso-protons at $110.78 \mathrm{ppm}$ and methyl-protons at 63.89 and 58.96 ppm; (b) ${ }^{1} \mathrm{H}-\mathrm{NMR}$ of $\left[\mathrm{DPPicFe} \mathrm{IV}^{\mathrm{IV}}=\mathrm{O}\right]^{+\cdot}$ with the highest chemical shifts at $22.67 \mathrm{ppm}$ and with no possibilities of assignation. 
The formation of the ferryl radical and the oxidation of $\mathrm{Fe}^{3+} \rightarrow \mathrm{Fe}^{4+}$ caused by $\mathrm{H}_{2} \mathrm{O}_{2}$ were confirmed by the ${ }^{1} \mathrm{H}-\mathrm{NMR}$ spectra under low temperature conditions that allow detecting such species. These data show the appearance of a new set of hyperfine-shifted resonances that are characteristic of $\mathrm{Fe}^{4+}$ ferriheme-like complexes, replacing the ones in the $\mathrm{Fe}^{3+}$ species of [FeDPPic] (Figure 6), [FeMPPic] (Supplementary Materials Figure S3) and [FePPPic] (Supplementary Materials Figure S4) [3].

The chemical shift displacement of the protons in the heme group is explained by the loss of $s=5 / 2$ in the quantum mixed spin character. Now that the $\mathrm{Fe}^{3+}$ ion has been substituted with $\mathrm{Fe}^{4+}$ with a $d^{4}$ configuration, which is coupled with the spin radical giving a $s_{\text {total }}=3 / 2$, this results in the decreasing of the sensitivity towards $s=3 / 2$ and $s=5 / 2$ contributions.

The positions of chemical shifts in the ${ }^{1} \mathrm{H}-\mathrm{NMR}$ [pinch-porphyrins $\mathrm{Fe}^{\mathrm{IV}}=\mathrm{O}{ }^{+\cdot}$ spectra inform us that the spin state of iron ion is lower than for the pinch-porphyrin parent compounds since the chemical shift responds to $\delta \alpha(s+1)$ [28,29]. The iron (IV) ion becomes more electronegative for the higher oxidation state and its bond with the nitrogen atom of pyridine proximal is shorter. The ion position respect to the porphyrin-ring decreases its electron-withdrawing effect on sigma and pi electrons. The ${ }^{1} \mathrm{H}-\mathrm{NMR}$ spectra for the [pinch porphyrins- $\left.\mathrm{Fe}^{\mathrm{IV}}=\mathrm{O}\right]^{+\cdot}$ correspond to a new magnetic structure.

The ${ }^{1} \mathrm{H}-\mathrm{NMR}$ studies of this pinch-porphyrin pi-cationic-radical, $\left[\mathrm{PFe}^{\mathrm{IV}}=\mathrm{O}\right]^{+\cdot}$ family, show that when there is no guaiacol in the reaction medium, the reaction between $\left[\mathrm{PFe}^{\mathrm{IV}}=\mathrm{O}\right]^{+\cdot}$ and $\mathrm{H}_{2} \mathrm{O}_{2}$ produces a new set of highly reactive compounds which immediately destroy the porphyrinic structures. The pinch porphyrin pi-cationic-radicals show lower spin states than the iron ion bond just to the pinch porphyrins, and this idea comes from the ${ }^{1} \mathrm{H}-\mathrm{NMR}$ and ESR magnetic studies. These reaction products show characteristics of the oxidation intermediate compounds of peroxidase enzymes, compounds I and II (Table 2).

Table 2. Selected ESR spectra data of compound I and compound II of peroxidases and their model compounds, contrasting the chemical shifts for [pinch porphyrinsFe $\left.\mathrm{IV}^{\mathrm{IV}}=\mathrm{O}\right]^{+\cdot}$ presented herein.

\begin{tabular}{ccc}
\hline Compound Source & $\begin{array}{c}\text { Chemical Shift } \\
\text { (ppm) }\end{array}$ & Reference \\
\hline Horseradish Peroxidase-I & 80,7 & {$[30]$} \\
H42A-Horseradish Peroxidase-I & $80,6.5$ & {$[31]$} \\
Cytochrome c peroxidase-I & 35,5 & {$[32]$} \\
Chloroperoxidase-I & 48,8 & {$[33]$} \\
Chloro(2-oxa-3-oxotetramesitylporphinato)Fe(III) & $20,7.6$ & {$[34]$} \\
Chloro(2-oxa-3-oxotetrakis(2,6-dichlorophenyl)-porphinato)Fe(III) & $20,8.9$ & {$[34]$} \\
(py)tetra-m-tolyporphyrin)Fe(III)-I & $-38,-17.7$ & {$[28]$} \\
Manganese Peroxidase-I & $40,7.7$ & {$[35]$} \\
Lignin peroxidase-I & $42,7.4$ & {$[35]$} \\
[FePPPic]-I & $39,7.12$ & This work \\
[FeMPPic]-I & $29,7.02$ & This work \\
[FeDPPic]-I & $19,7.06$ & This work \\
\hline
\end{tabular}

\subsection{ESR Spectroscopy}

The ESR spectra of $\left[\mathrm{PPicFe}^{\mathrm{IV}}=\mathrm{O}\right]^{+}$clearly showed the transformation of the quantum mixed phenomena spin species to the $\mathrm{Fe}^{4+}$. The picdien axial ligand has shown the unexplained ability of its coordination to these porphyrins, to produce only two ligand-field $\mathrm{Fe}^{+3}$ environments in the complexes, these being $s=3 / 2$ and $s=5 / 2$. To further characterize these species, many repeated ESR experiments were carried out in our laboratory showing that the signals correspond to the qms for the intermediates compounds [FePPPic]-I, [FeMPPic]-I and [FeDPPic]-I [3] (Figure 7).

Moreover, the two paramagnetic species $s=3 / 2, s=5 / 2$ are stabilized by the picdien ligand axially coordinated to the three different pinch porphyrins, this would correspond to the coexistence of structures of $\mathrm{Fe}(\mathrm{III})$ ion very small out-of-plane position and the out-of-plane position, respectively. 
The qms species with higher proportion of $s=5 / 2$ decrease when the $\mathrm{Fe}^{4+}$ is formed; hence, the spectral line shape changes to give the free radical a unique signal at $g=1.93$. The radical signal is near of the signal with $g=2$ corresponding to two axial ESR spectra for the three model intermediates of compound I (Figure 5). The signal at $\mathrm{g} \sim 4$, corresponding to the $s=3 / 2$ increases and its line shape is very similar in the three pinchporphyrins radical cationic ferryl (Table 3) [32].

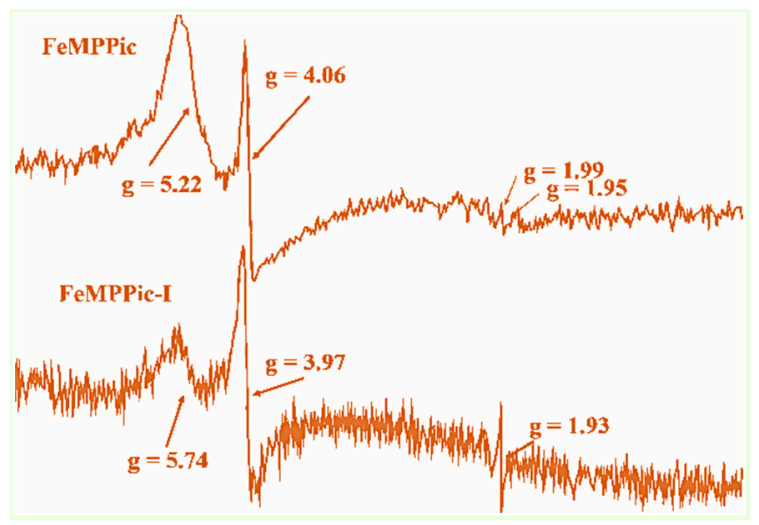

Figure 7. Top: ESR spectrum of [FeMPPic] at $77 \mathrm{~K}$ in methanol solution with two species of Fe(III) with qms; $s=3 / 2, S=5 / 2$, species with $g=5.22,1.99$ contains more $s=5 / 2$ in qms; species with $\mathrm{g}=4.06$, 1.95 , contains more $s=3 / 2$ in qms. Bottom: [FeMPPic]-I with two species of iron ion, one with $g=5.74$ and higher percentage of this species in qms but in less proportion than the second species $(\mathrm{g}=3.97$ ) with $s=3 / 2$. At $g=1.93$ the radical signal is present.

Table 3. ESR spectra data of compound I and compound II intermediates of peroxidases and peroxidase models, contrasting the chemical shifts for [pinch porphyrinsFe $\mathrm{IV}^{\mathrm{IV}}=\mathrm{O}^{+\cdot}$ presented in this work.

\begin{tabular}{ccc}
\hline Compound Source & g Values & Reference \\
\hline Horseradish Peroxidase-I & $6.38,5.38,2.00$ & {$[35]$} \\
Pea ascorbate peroxidase-I & $6.04,5.27,1.99$ & {$[36]$} \\
Chloro(2-oxa-3-oxotetramesitylporphinato)Fe(III) & $3.98,2.00$ & {$[33]$} \\
Chloro(2-oxa-3-oxotetrakis(2,6-dichlorophenyl)-porphinato)Fe(III) & $3.72,1.99$ & {$[33]$} \\
4,6-di(tert-Butyl)-2-aminophenolCu(II)-I & $2.32,2.06$ & {$[37]$} \\
2-Anilino-4,6-di(tert-butyl)-2-aminophenolCu(II)-I & $2.27,2.07$ & {$[37]$} \\
Oxyferrous hp450scc-DHC-I & $2.44,2.25,1.91$ & {$[38]$} \\
Lignin peroxidase-I & $6.6,1.95$ & {$[39]$} \\
[FePPPic]-I & $5.88,4.03,1.93$ & This work \\
[FeMPPic]-I & $5.74,3.98,1.93$ & This work \\
[FeDPPic]-I & $5.88,4.10,1.95$ & This work \\
\hline
\end{tabular}

Figure 8 displays the ESR spectra of compound-I from $\left[\mathrm{PPPicFe}^{\mathrm{IV}}=\mathrm{O}\right]^{+\cdot},\left[\mathrm{MPPicFe}{ }^{\mathrm{IV}}=\mathrm{O}\right]^{+\cdot}$ and $\left[\mathrm{DPPicFe}{ }^{\mathrm{IV}}=\mathrm{O}^{+}\right.$. . These spectra present two species of iron ion with qms, $s=3 / 2, s=5 / 2$, and in major proportion the $s=5 / 2$ species (g values of 5.74,5.88). Other species only with $s=3 / 2$ (g values $\sim 4$, $1.9)$, this last signal is typical of a radical.

ESR spectra of FePPic-I show a radical signal different to the reported for HRP-I [35-40]; although, it is possible that these signals contain the one at $\mathrm{g} \sim 2$ for axial spectra of qms species and the axial spectra with $s=3 / 2$. It is clear that each ESR spectrum is a snapshot of some of the changes in the oxidation state of the iron ion. When we finished each FePPic-I spectrum, we tried to obtain the following one, then the signal was quenched. 


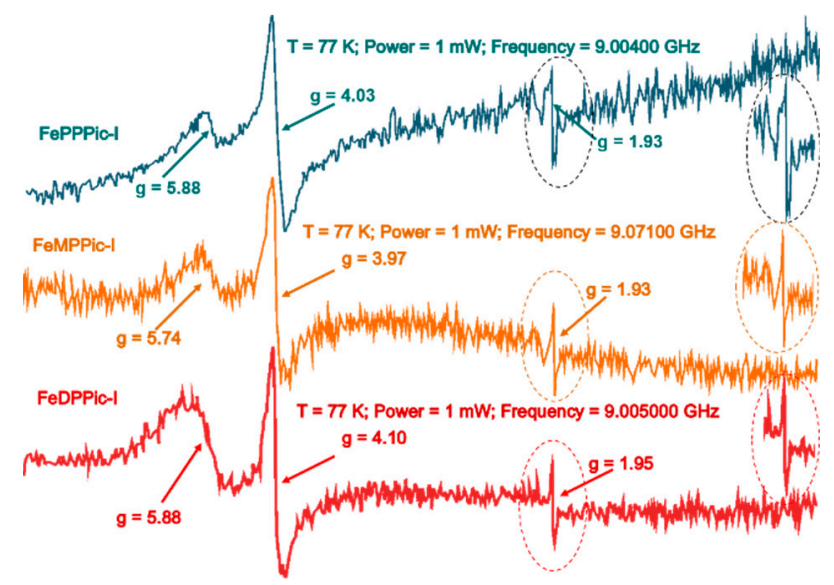

Figure 8. ESR axial spectra of $\left[\mathrm{PPicdienFe} \mathrm{IV}^{\mathrm{IV}}=\mathrm{O}\right]^{+\cdot}$ with species of iron ion at higher energy with qms ( $\mathrm{g}>5.7)$, proportion decrease from [FePPPic]-I $>$ [FeMPPic]-I $>$ [FeDPPic]-I. Species with $s=3 / 2(\mathrm{~g} \sim 4)$ and with the highest proportion in each sample. The $s=3 / 2$ corresponds to three unpaired spins, which stem of the Fe(IV) ion low spin $(s=1)$ ferromagnetically coupled with radical with $s=1 / 2$, giving a total spin of $s=3 / 2$.

\subsection{Reaction Mechanism}

Our proposed reaction mechanism is shown in Scheme 2 [3] starting from compound 0 to produce compounds I and II, which are obtained more or less quickly depending on the stability of compound 0 . Although, the activation energies to produce compound 0, quantified in other work [40], were smaller for [FePPPic] $\left(5.4 \mathrm{Kcal} \cdot \mathrm{mol}^{-1}\right)<$ [FeMPPic] $\left(7.84 \mathrm{Kcal} \mathrm{mol}^{-1}\right)<[\mathrm{FeDPPic}]\left(8.11 \mathrm{Kcal} \mathrm{mol}^{-1}\right)$ (Figure 9). These values of $E_{\text {act }}$ inform us that Fe(III) ion in the [FePPPic] is more electronegative than in [FeMPPic] and [FeDPPic], which is consistent with the electron-withdrawing vinyl groups that are present in positions 2, 4 of the porphyrin ring. The ethyl and vinyl groups present in [FeMPPic] and [FeDPPic] are electron-donors and decrease the Fe(III) electronegativity.

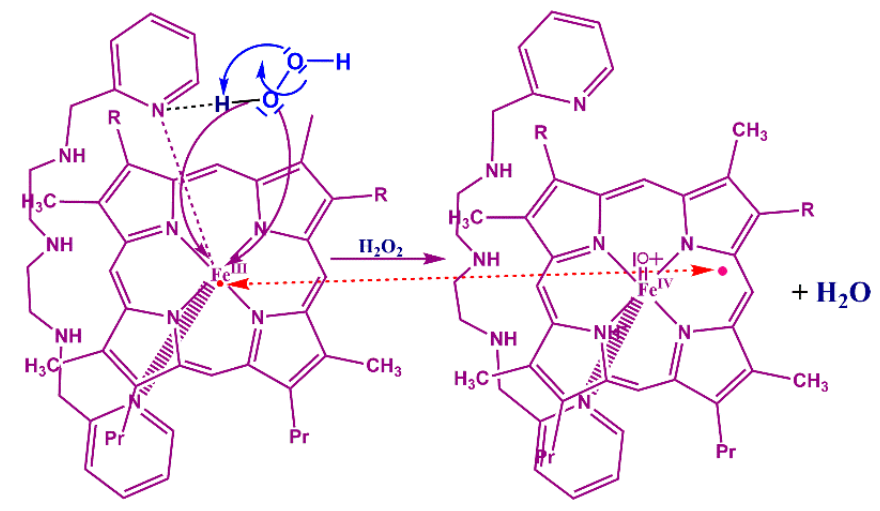

Scheme 2. The intermediate compound 0 formed faster if the Fe (III) has less stability to receive less electronic contribution of its porphyrin macroligand. 


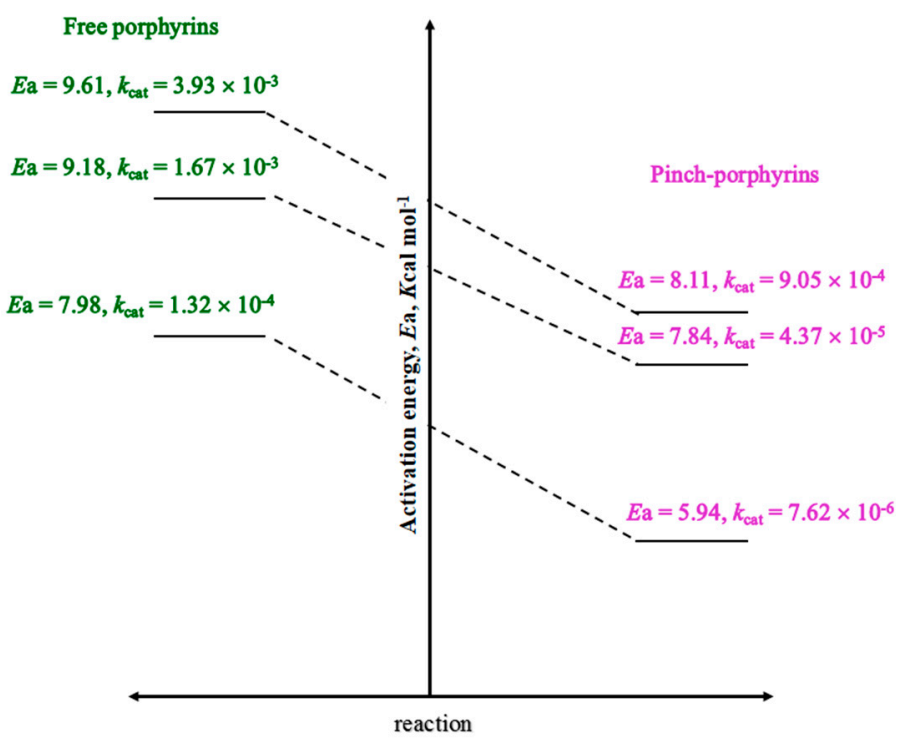

Figure 9. Comparison of the activation energies from three compounds with and without the pinch-axial-ligand.

\section{Material and Methods}

The complexes [1,9-bis(2-pyridyl)-2,5,8-triazanonane]-(protoporphyrinato)iron(III) [FePPPic], -(mesoporphyrinato)-iron(III) [FeMPPic] and -(deuteroporphyrinato)iron(III) [FeDPPic]], were synthesized starting from the parent compounds chloro-(porphyrinato)iron(III), -(mesoporphyrinato)iron(III) and -(deuteroporphyrinato)iron(III) and 1,9-bis(2-pyridyl)-2,5,8-triazanonane (pic) [3]. Electronic spectra were measured at $298 \mathrm{~K}$ on a UV-3100 spectrophotometer (Shimadzu, Kyoto, Japan) in methanol solution of pinch-porphyrins in the range $200-800 \mathrm{~nm}$, Table 4 summarizes these conditions. The microwave X-band $(9.4 \mathrm{GHz})$ of a JEOL JES-RES3X spectrometer (Jeol Co. Tokyo, Japan), power of $1 \mathrm{~mW}$, field amplitude $0-500 \mathrm{mT}$, and frequency of: $9.00400 \mathrm{GHz}$ for [[FePPPic]], $9.07100 \mathrm{GHz}$ for [FeMPPic] and $9.005000 \mathrm{GHz}$ for [FeDPPic]. NMR measurements were carried out on a JEOL Eclipse 300 spectrometer (Jeol Co. Tokyo, Japan) at $213 \mathrm{~K}$, frequency $300 \mathrm{MHz}$, pulse width $6.7 \mathrm{~s}$, No. repetitions 128, FT size 131072, total acquisition time $5 \mathrm{~min}$, field amplitude of -80 to $+80 \mathrm{ppm}$, acquisition time $1.422 \mathrm{~s}$ [FePPPic], $0.800 \mathrm{~s}$ [FeMPPic] and $0.800 \mathrm{~s}$ [FeDPPic].

Table 4. Conditions of Compound I and II formation, starting of pinchporphyrins by spectroscopy of UV-Vis at $25^{\circ} \mathrm{C},{ }^{1} \mathrm{H}-\mathrm{NMR}$ at $-50{ }^{\circ} \mathrm{C}$ and ESR at $77 \mathrm{~K}$.

\begin{tabular}{ccc}
\hline [Pinch-Porphyrin] & ca [Pinch-Porpyrin $]_{f}$, Methanol, $\mathbf{m M}$ & ca $\left[\mathbf{H}_{\mathbf{2}} \mathbf{O}_{\mathbf{2}}\right]_{\mathbf{f}}$, Aqua, $\mathbf{m M}$ \\
\hline$[$ FePPPic $]$ & 0.0098 & 0.123 \\
{$[$ FeMPPic $]$} & 0.0487 & 1.14 \\
{$[$ FeDPPic $]$} & 0.057 & 1.34 \\
\hline
\end{tabular}

The pinch-porphyrins and hydrogen peroxide concentrations for ESR and NMR- ${ }^{1} \mathrm{H}$ studies in methanolic solutions were the same that for UV-Vis studies.

\section{Conclusions}

More information to explain the always interesting mechanism of the intermediates resulting from the oxidation process of the peroxidases enzymes is been added. Three new pinch-porphyrin $\pi$-radical cationic products, which are formed by the oxidation process of enzyme-like synthetic compounds, were observed and characterized by UV-Vis, ${ }^{1} \mathrm{H}-\mathrm{NMR}$ and ESR spectroscopies. It is important to note that a unique half lifetime is seen in the present intermediates, a characteristic that allowed 
us to perform all the analyses. As well, their kinetic behaviors are consistent with previous results reported for possible intermediate model compounds proposed to be responsible for catalytic activity of peroxidases. Importantly, a correlation between the ratios of their qms properties with the catalytic activity was established by the integration of these data. It is clear that the limiting step in the oxidation process is the formation of compound 0 , being the heterolytic cleavage the determinant factor in the balance of the overall pathway.

Supplementary Materials: Supplementary materials can be accessed at: http://www.mdpi.com/1420-3049/ 21/7/804/s1.

Acknowledgments: The present work has been supported by Vicerrectoría de Investigación y Estudios de Posgrado from BUAP, Divulgation of Science, Proyects No. REOY-NAT14,15-G. We thank Sandra E. Pineda Sanabria (University of Alberta, Department of Biochemistry) for her help during the redaction of the manuscript and Sylvain Bernés (IFUAP-BUAP) for his contribution in results discussion.

Author Contributions: S.H.A. and Y.R.O. integrate the data wrote and design the manuscript. U.A.A. and A.L.G. performed all the experiments except the ESR measurements. D.R.R. and R.Z.U. performed and discuss the ESR studies.

Conflicts of Interest: All author declare no conflict of interest.

\section{References}

1. Lehninger, A.L.; Nelson, D.L.; Cox, M.M. Lehninger Principles of Biochemistry, 5th ed.; Ahr, K., Ed.; W. H. Freeman and Company: New York, NY, USA, 2008.

2. Hernández-Anzaldo, S.; Sánchez-Morales, N.; Alcántara-Flores, J.L.; Gutiérrez-Pérez, R.; Zamorano-Ulloa, R.; Escudero, R.; de Hoz, M.J.R.; Reyes-Ortega, Y. ESR and magnetic studies of octahedral $\left[\mathrm{Fe}(\mathrm{III})(\mathrm{Cl})(\mathrm{pcd})\left(\mathrm{H}_{2} \mathrm{O}\right)(\mathrm{DMSO})\right](\mathrm{pcd}=$ pyridine-2,6-dicarboxylato) compound showing $\mathrm{Fe}(\mathrm{III})$ species with different spin states in solution. J. Mol. Struct. 2013, 1040, 22-26. [CrossRef]

3. Reyes-Ortega, Y.; Alvarez-Toledano, C.; Ramírez-Rosales, D.; Sánchez-Sandoval, A.; González-Vergara, E.; Zamorano-Ulloa, R. Pinch-porphyrins, new spectroscopic and kinetic models of peroxidases. Dalton Trans. 1998, 667-674. [CrossRef]

4. Drago, R.S. Physical Methods for Chemists, 2nd ed.; Saunders College Publishing: Philadelphia, PA, USA, 1992.

5. Dunford, B. Heme Peroxidases; Wiley-VCH: New York, NY, USA, 1999.

6. Reed, J.C.A.; Mashiko, T.; Bentley, S.P.W.; Kastner, M.E.; Scheidt, W.R.; Spartalian, K.; Lang, G. The missing heme spin state and a model for cytochrome $c^{\prime}$. The mixed $S=3 / 2,5 / 2$ intermediate spin ferric porphyrin: perchlorate(meso-tetraphenylporphinato)iron(III). J. Am. Chem. Soc. 1979, 101, 2948-2958. [CrossRef]

7. Jennifer, S.; Stillman, M.J.; Dunford, H.B. Photochemical reactions of horseradish peroxidase compounds I and I1 at room temperature and $10^{\circ} \mathrm{K}$. Biochemistry 1975, 14, 3183-3188.

8. Reed, C.A.; Guiset, F. A “Magnetochemical" Series. Ligand Field Strengths of Weakly Binding Anions Deduced from $S=3 / 2,5 / 2$ Spin State Mixing in Iron(III) Porphyrins. J. Am. Chem. Soc. 1996, 118, 3281. [CrossRef]

9. Jones, P.; Dunford, H.B. On the mechanism of compound I formation from peroxidases and catalases. J. Theory Biol. 1977, 69, 457-470. [CrossRef]

10. Jones, P.; Dunford, H.B. The mechanism of compound I formation revisited. J. Inorg. Biochem. 2005, 99, 2292-2298. [CrossRef] [PubMed]

11. King, T.E.; Mason, H.S.; Morrison, M. Oxidases and Related Redox Systems; University Park Press: Baltimore, MD, USA, 1973; Volume 1, pp. 388-401.

12. Sanchez-Sandoval, A.; Ramirez-Rosales, D.; Zamorano-Ulloa, R.; Alvarez-Toledano, C.; Moya-Cabrera, M.; Reyes-Ortega, Y. New pinch-porphyrin complexes with quantum mixed spin ground state $S=3 / 2,5 / 2$, of iron(III) and their catalytic activity as peroxidase. Biophys. Chem. 2003, 106, 253-265. [CrossRef]

13. Saunders, B.C.; Holmes-Siedle, A.G.; Stark, B.P. Peroxidase; Butterworths: London, UK, 1964; Volume 3, p. 1015.

14. Traylor, T.G.; Lee, W.A.; Stynes, D.V. Model compound studies related to peroxidases. Mechanisms of reactions of hemins with peracids. J. Am. Chem. Soc. 1984, 106, 755-764. [CrossRef] 
15. Bonagura, C.A.; Bhaskar, B.; Shimizu, H.; Li, H.; Sundaramoorthy, M.; McRee, D.E.; Goodim, B.G.; Poulos, T.L. High-Resolution Crystal Structures and Spectroscopy of Native and Compound I Cytochrome $c$ Peroxidase. Biochem. 2003, 42, 5600-5608. [CrossRef] [PubMed]

16. Toledo, J.C.; Audi, R.; Ogusucu, R.; Monteiro, G.; Soares Netto, L.E.; Augusto, O. Horseradish peroxidase compound I as a tool to investigate reactive protein-cysteine residues: From quantification to kinetics. Free Radic. Biol. Med. 2011, 50, 1032-1038. [CrossRef] [PubMed]

17. Hewson, W.D.; Hager, L.P. Oxidation of horseradish peroxidase compound II to compound I. J. Biol. Chem. 1979, 254, 3182-3186. [PubMed]

18. Tanaka, M.; Matsuura, K.; Yoshioka, S.; Takahashi, S.; Ishimori, S.; Hori, S.; Morishima, I. Activation of hydrogen peroxide in horseradish peroxidase occurs within $\sim 200 \mathrm{~ms}$ observed by a new freeze-quench device. Biophys. J. 2003, 84, 1998-2004. [CrossRef]

19. Newcomb, M.; Zhang, R.; Chandrasena, R.E.P.; Halgrimson, J.A.; Horner, J.H.; Makris, T.M.; Sligar, S.G. Cytochrome P450 compound I martin newcomb. J. Am. Chem. Soc. 2006, 128, 4580-4581. [CrossRef] [PubMed]

20. Takahashi, S.; Ogawa, T.; Inoue, K.; Masuda, T. Characterization of cytosolic tetrapyrrole-binding proteins in Arabidopsis thaliana. Photochem. Photobiol. Sci. 2008, 7, 1216-1224. [CrossRef] [PubMed]

21. Wang, X.; Peter, S.; Kinne, M.; Hofrichter, M.; Groves, T. Detection and kinetic characterization of a highly reactive heme-thiolate peroxygenase compound I. J. Am. Chem. Soc. 2012, 134, 12897-12900. [CrossRef] [PubMed]

22. De Jesus-Bonilla, W.; Cortes-Figuero, J.E.; Souto-Bachiller, F.A.; Rodriguez, L.; Lopez-Garriga, J. Formation of compound I and compound II ferryl species in the reaction of hemoglobin I from Lucina pectinata with hydrogen peroxide. Arch. Biochem. Biophys. 2001, 390, 304-308. [CrossRef] [PubMed]

23. Jayaraj, K.; Gold, A.R.; Austin, N.L.; Ball, M. Compound I and compound II analogues from porpholactones. Inorg. Chem. 1997, 36, 4555-4566. [CrossRef] [PubMed]

24. Oszajca, M.; Franke, A.; Drzewiecka-Matuszek, A.; Brindell, M.; Stochel, G.; van Eldik, R. Temperature and pressure effects on $\mathrm{C}-\mathrm{H}$ abstraction reactions involving compound I and II mimics in aqueous solution. Inorg. Chem. 2014, 53, 2848-2857. [CrossRef] [PubMed]

25. La Mar, G.N.; de Ropp, J.S.; Smith, K.M.; Langry, K.C. Proton nuclear magnetic resonance investigation of the electronic structure of compound I of horseradish peroxidase. J. Biol. Chem. 1981, 256, 237-243. [PubMed]

26. Asokan, A.; de Ropp, J.S.; Newmyer, S.; de Montellano, P.O.; La Mar, G.L. Solution ${ }^{1}$ H NMR of the molecular and electronic structure of the heme cavity and substrate binding pocket of high-spin ferric horseradish peroxidase: Effect of His42Ala mutation. J. Am. Chem. Soc. 2001, 123, 4243-4254. [CrossRef] [PubMed]

27. Banci, L.; Bertini, I.; Pease, E.A.; Tien, M.; Turano, P. ${ }^{1} \mathrm{H}$ NMR Investigation of Manganese Peroxidase from Phanerochaete chrysosporium. Biochemistry 1992, 31, 10009-10017. [CrossRef] [PubMed]

28. Kurland, R.J.; Little, R.G.; Davis, D.G.; Ho, C. Proton Magnetic Resonance Study of High- and Low-Spin Hemin Derivatives. Biochemistry 1971, 10, 2237-2246. [CrossRef] [PubMed]

29. Budd, D.L.; La Mar, G.N.; Langry, K.C.; Smith, K.M.; Nayyir-Mazhir, R. ${ }^{1}$ H-NMR study of high-spin ferric natural porphyrin derivatives as models of methemoproteins. J. Am. Chem. Soc. 1979, 101, 6091-6096. [CrossRef]

30. Savenkova, M.I.; Satterlee, J.E.; Erman, J.E.; Siems, W.F.; Helms, G. Expression, purification, characterization, and NMR studies of highly deuterated recombinant cytochrome $c$ peroxidase. Biochemistry 2001, 40, 12123-12131. [CrossRef] [PubMed]

31. Wang, X.; Tachikawa, H.; Yi, X.; Manoj, K.M.; Hager, L.P. The two-dimensional NMR study of the heme active site structure of chloroperoxidase. J. Biol. Chem. 2003, 278, 7765-7774. [CrossRef] [PubMed]

32. Balch, A.L.; La Mar, G.N.; Latos-Grazynski, L.; Renner, M.W.; Thanabal, V. Nuclear magnetic resonance studies of axial amine coordination in synthetic ferryl, porphyrin complexes and in ferryl myoglobin. J. Am. Chem. Soc. 1985, 107, 3003-3007. [CrossRef]

33. Gold, A.; Jayaraj, K.; Doppelt, P.; Weis, R.; Chottard, G.; Bill, E.; Ding, X.; Trautwein, A.X. Oxoferryl complexes of the halogenated (porphinato)iron catalyst (tetrakis(2,6-dichlorophenyl)porphinato)iron. J. Am. Chem. Soc. 1988, 110, 5756-5761. [CrossRef]

34. Khindaria, A.; Aust, S. EPR detection and characterization of lignin peroxidase porphyrin $\pi$-cation radical. Biochemistry 1996, 35, 13107-13111. [CrossRef] [PubMed] 
35. Davydov, R.; Strushkevich, N.; Smil, D.; Yantsevich, A.; Gilep, A.; Usanov, S.; Hoffman, B.H. Evidence that compound $\mathrm{I}$ is the active species in both the hydroxylase lyase steps by which P450scc converts cholesterol to pregnenolone: EPR/ENDOR/cryoreduction/annealing studies. Biochemistry 2015, 54, 7089-7097. [CrossRef] [PubMed]

36. Jones, D.K.; Dalton, D.A.; Rosell, F.I.; Lloyd-Raven, E. Class I heme peroxidases: Characterization of soybean ascorbate peroxidase. Arch. Biochem. Biophy. 1998, 360, 173-178. [CrossRef] [PubMed]

37. Loginova, N.V.; Kovalchuk, T.V.; Zheldakova, R.A.; Osipovich, N.P.; Sorokin, V.L.; Polozov, G.I.; Ksendzova, G.A.; Glushonok, G.K.; Chernyavskaya, A.A.; Shadyro, O.I. Synthesis and biological evaluation of copper (II) complexes of sterically hindered o-aminophenol derivativesas antimicrobial agents. Bioorg. Med. Chem. Lett. 2006, 16, 5403-5407. [CrossRef] [PubMed]

38. Fujii, H.; Yoshimura, T.; Kamada, H. ESR studies of $\mathrm{A}_{1 \mathrm{u}}$ and $\mathrm{A}_{2 \mathrm{u}}$ oxoiron(IV) porphyrin $\pi$-cation radical complexes. Spin coupling between ferryl iron and $\mathrm{A}_{1 \mathrm{u}} / \mathrm{A}_{2 \mathrm{u}}$ orbitals. Inorg. Chem. 1996, 35, 2373-2377. [CrossRef] [PubMed]

39. Khindaria, A.; Yamazaki, I.; Aust, S.D. Veratryl alcohol oxidation by lignin peroxidase? Biochemistry 1995, 34, 16860-16869. [CrossRef] [PubMed]

40. Reyes-Ortega, Y.; Arellano-Merino, C.; Mejía-Rodríguez, J.; Zamorano-Ulloa, R. Activation parameters of pinch-porphyrin complexes, models of peroxidase enzymes. Inf. Technol. 2002, 13, 65-71.

Sample Availability: Samples of the obtained compounds are available from the authors.

(C) 2016 by the authors; licensee MDPI, Basel, Switzerland. This article is an open access article distributed under the terms and conditions of the Creative Commons Attribution (CC-BY) license (http:/ / creativecommons.org/licenses/by/4.0/). 